\title{
Healthy cities and public health news
}

$\mathrm{T}$ Topics at the Canadian Public Health Association annual meeting, May 27-29 in Toronto, ranged from decriminalizing drugs such as marijuana, heroin and cocaine, to new surveillance of health inequalities. Designing healthier cities, difficulties measuring the true burden of dementia, violence against Aboriginal women, and lesbian, gay, bisexual and transgender health were also discussed, as detailed below.

\section{Healthy cities}

Rethinking how we design cities may be the key to greater health and happiness, urbanist Charles Montgomery told participants in a May 29 plenary.

He shared the story of a devastating heat wave that hit Chicago, Illinois, in 1995, killing more than 700 people in a matter of days. In the aftermath, epidemiologists learned that many of the deceased were poor and some didn't have air conditioning, but all had one thing in common: social disconnection.

The design of cities can either increase or heal that disconnection, said Montgomery, citing evidence that people who live in car-dependent suburban communities are less likely to know and trust their neighbours, vote, volunteer or eat dinner with their families.

Physical distance is central to the problem, he explained. Too much distance is alienating, while too little is affronting, as anyone on a crowded city bus can attest. Indeed, surveys show the happiest commuters are those who walk or bike. The ability to do either is mitigated by distance and design.

Happy cities - those with citizens who report higher levels of happiness - take these factors into account. Distances between home, school, work and play are made smaller by mixed-use development; streets have protected bike lanes, lower speed limits and wider sidewalks; neighbourhoods are punctuated by community gardens, parks and other social spaces.

From Portland, Oregon, to Bogota, Colombia, places that have newly intro-

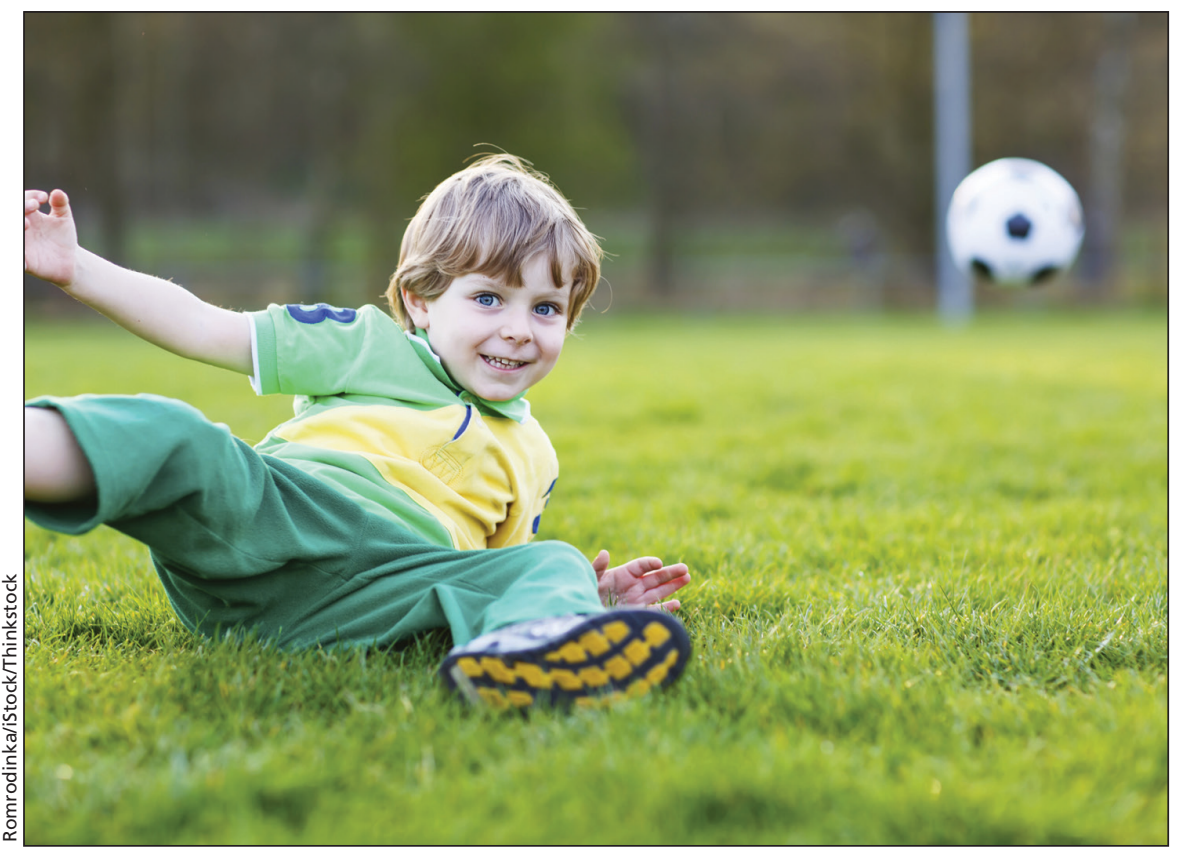

The design of cities, including green spaces and walking-friendly features, can help make people feel connected.

duced some or all of these measures have seen "positive effects radiating out," said Montgomery. "People slept better, scored better on tests of psychological wellbeing, and social trust went up."

The installation of a light-rail network in Charlotte, North Carolina, was associated with lower body weights among those who took the train to work. Meanwhile, experiments to create sidewalks that encourage socializing in New York City and San Francisco found that these changes also encouraged shopping.

Dr. Joel Kettner, Manitoba's former chief provincial public health officer, quipped on Twitter that "correlation does not necessarily equal causation.'”

Montogmery, however, said these anecdotes indicate that striving for happier cities isn't a "frivolous" endeavour. "The happy city, the connected city, the healthy city and the wealthy city are all the same place."

\section{Measuring dementia}

Canadian statistics on the prevalence and economic burden of dementia and related cognitive disorders are widely inconsistent and should be used with caution, warned participants in a May 29 panel.

The Alzheimer's Society of Canada predicts that the total cost of dementia will skyrocket from $\$ 33$ billion per year to more than $\$ 293$ billion by 2040 — an estimate based on data from the Canadian Study of Health and Aging, which followed 10000 participants over a decade.

Estimates derived from this study differ widely from those derived from other datasets. It all comes down to how the data are collected and interpreted, says Parminder Raina, a professor in the department of clinical epidemiology and biostatistics at McMaster University in Hamilton.

Statistics Canada surveys, for example, generally underestimate the prevalence of dementia and related cognitive disorders, because "people have to be cognitively intact to give consent and participate, and right away that reduces the prevalence," explained Raina.

Studies in this field also rely heavily on self-assessment, making it hard to 
differentiate between types of cognitive impairment, "beyond the fact that your doctor said you have dementia," he noted. Meanwhile, almost two-thirds of people with dementia have not received a formal diagnoses, "so there is a lot of undiagnosed burden that we also have to be able to quantify."

Measures used to do this vary "hugely," and are not generalizable; for example, questions about memory are more useful as a measure of cognitive impairment in older populations, but less so for younger, female or multilingual participants.

Using this data to make sweeping predictions or inform national policy "will come up with wrong estimates," said Raina.

\section{Violence and Aboriginal women}

Canada's inaction on violence against indigenous women is a national tragedy, said activists and public health experts in the May 27 plenary.

Abuse, poverty and years of systemic racism are determining factors in the poor health faced by Aboriginal Canadians, said Dawn Harvard, president of the Ontario Native Women's Association. “This isn't an Aboriginal problem or a women's problem; it's a Canadian problem."

Nearly 1200 Aboriginal girls have been murdered or gone missing since 1980, according to police estimates. Aboriginal women are three times more likely to be victims of violence and five times more likely to die of violence than other Canadians. Over $40 \%$ live in poverty.

These disparities are closely linked with poor health outcomes, added Harvard. "It's not surprising that our women experience the poorest health, lowest life expectancies and highest levels of chronic disease in Canada."

She and other speakers called for a federal inquiry and plan of action to address these inequalities.

\section{LGBT health}

Myopic focus on sexuality in public health programs for lesbian, gay, bisexual and transgender (LGBT) people undermines overall well-being, levelled a May 27 panel.

Public health initiatives need to think outside the "knee to navel" box to address the bigger picture of LGBT health, said Daniel Pough, a knowledgetransfer-exchange coordinator for the Gay Men's Sexual Health Alliance of
Ontario. "We have more moving parts — body, mind and spirit — aside from our sexual organs."

According to Nathan Lachowsky, an epidemiologist in population medicine at the University of Guelph in Ontario, a new approach might foster "relationship satisfaction, fitness, community engagement, social supports, and resilience," in addition to safer sex.

Lorna Boschman, project manager of the Cancer's Margins Research Study at the University of British Columbia in Vancouver, noted that transgender people, who face many unique barriers unrelated to sexuality, are particularly disadvantaged by the current approach.

For example, transgender men are especially affected by breast and gynaecological cancers, but may not be able to access or obtain provincial coverage for screening if they've changed their gender on paper.

Just entering a women's clinic as "the only trans-man in the room" can be daunting, said Boschman. "Our wellmeaning, one-size-fits-all approach too often gives messages of unwelcome." — Lauren Vogel, CMAJ

CMAJ 2014. DOI:10.1503/cmaj.109-4823 